\title{
Guía práctica para realizar videoconsultas
}

\author{
A practice guide for video consultations
}

\section{Comentado de:}

\section{Greenhalgh T. BJGP Life, 18 Mar $2020^{1}$}

\section{Resumen}

La utilización de la tecnología de la información y comunicación (TIC) en los sistemas de salud se encuentra actualmente en un proceso de creciente implementación, con gran variabilidad de acuerdo al área geográfica y al nivel socio-económicoeducativo de la población a la que va destinado este servicio. Por otro lado, la actual pandemia por coronavirus aceleró los procesos de comunicación virtual entre profesionales de la salud y pacientes, fundamentalmente a través de videollamadas, lo que nos obliga a cuestionarnos su modo de implementación.

Fue en este contexto, que en marzo de 2020 la revista BJGP life publicó una guía práctica para la utilización de video-consultas en atención primaria, que aborda cinco temáticas principales:

1. Cuándo es apropiado ofrecer una video-consulta en el ámbito de la atención primaria y cuando no.

2. Cómo prepararse antes de realizarlas.

3. Consejos para que el profesional optimice la calidad de la video-consulta.

4. Consejos para el paciente obtenga el mayor provecho posible de ellas.

5. Evidencia sobre su calidad y seguridad.

1) Cuándo es apropiado ofrecer una video-consulta en el ámbito de la atención primaria y cuando no es conveniente hacerlo. a) Situaciones apropiadas para ofrecer videoconsultas

Consultas vinculadas a COVID-19

La guía considera apropiado ofrecer una video-consulta en ámbito de la atención primaria cuando: el médico debe aislarse para proteger la fuerza laboral de profesionales de la salud, cuando el paciente estuvo en contacto estrecho con un caso confirmado o sospechoso de COVID-19, cuando el paciente tiene manifestaciones clínicas vinculadas a COVID-19 -esta alternativa puede depender de las directivas de las autoridades sanitarias locales, que en algunos lugares han establecido que los 14 días de aislamiento de los pacientes infectados transcurran en alguna locación dependiente del sistema de salud, como un hospital o un hotel alquilado a tal efecto-, cuando el paciente está en buenas condiciones de salud pero está ansioso y requiere que se le brinde alguna palabra tranquilizadora, cuando el paciente vive en una comunidad aislada y requiere algún tipo de comunicación con el equipo de salud.

Por otro lado, cuando los pacientes sólo necesitan obtener información general sobre la enfermedad por COVID-19, esta guía recomienda dirigirlos a algún sitio web informativo o bien, ofrecerles algún mensaje grabado.

\section{Consultas no vinculadas a COVID-19}

La guía destaca que la atención por video-consultas puede ser de ayuda para solucionar problemas administrativos (p. ej. recetas, autorizaciones de interconsultas a otros especialistas), brindar asesoramiento/consejería y optimizar algún proceso de triage cuando una llamada telefónica es insuficiente, y también contribuye a brindar cuidados a pacientes en seguimiento por enfermedades crónicas, especialmente las que definen que el paciente aumente el riesgo de desarrollar enfermedad grave por COVID19 (enfermedades respiratorias o cardiovasculares crónicas, diabetes, etc.).

\section{b) Situaciones no apropiadas para ofrecer videoconsultas}

Pacientes potencialmente graves y de alto riesgo, en quienes sea necesario realizar un examen físico, y pacientes que tengan barreras para la utilización de plataformas digitales, sean estas transitorias (confusión) o permanentes y/o progresivas (demencia).

\section{2) Cómo prepararse antes de realizar la teleconsulta}

Se recomienda particularmente que las instituciones de salud que promueven la realización de consultas por telemedicina produzcan piezas de información para sus usuarios que describan, en términos sencillos, la tecnología que necesitarán para optimizar los procesos de comunicación a través de videoconsultas; mantengan un sitio web actualizado en el que puedan constatarse las citas programadas y las no programadas; y capaciten al personal de salud para la realización de este tipo de consultas.

Antes de realizar la teleconsulta, se recomienda realizar entrevistas simuladas o de entrenamiento y desarrollar los enlaces con el soporte técnico para los usuarios y usuarias de los sistemas de telemedicina. Durante esta etapa también es importante brindar soporte técnico respecto de la optimización de la configuración del acceso a Internet y el uso de los dispositivos necesarios para llevar a cabo la videoconsulta (hadware, software, plataforma), así como entrenar a los usuarios en planes de contingencia sobre qué hacer si falla el enlace de videollamada (p. ej., continuar la consulta por teléfono).

\section{3) Consejos para optimizar la calidad de la videoconsulta}

Antes del encuentro con el paciente, el profesional debe confirmar que la teleconsulta es apropiada para ese paciente en ese momento. Se aconseja tener el número de teléfono del paciente por si la videollamada falla, usar una habitación privada y bien iluminada para realizar el contacto, asegurarse el acceso a la historia clínica y verificar que la tecnología que se utilizará esté funcionando.

Al iniciar la consulta, se aconseja registrar el consentimiento verbal del paciente para una consulta por videollamada, comunicar que la consulta es similar a la estándar y que lo que se converse durante dicha entrevista será tratado en forma confidencial. Además se debe presentar a todas las personas en la sala (incluyendo a quienes se encuentren fuera de cámara) y solicitar que el paciente haga lo mismo.

Durante la consulta, se recomienda mirar a la pantalla, informando al paciente cuando el profesional esté ocupado tomando notas o leyendo algo en otra pantalla, y realizar registros escritos de la misma manera que se hubiera hecho presencialmente.

Al finalizar el encuentro con el paciente, el médico debe resumir los puntos clave de la consulta, confirmar y registrar si el paciente se sintió a gusto con la entrevista por este medio, si necesita alguna aclaración, y despedirse de él o ella antes de cerrar la conexión.

\section{4) Consejos para pacientes sobre las teleconsultas en general}

La guía recomienda a cada paciente, en primer lugar, reflexionar sobre si la videoconsulta es adecuada para esa persona, teniendo en cuenta cuál es el problema que desea resolver. La información visual le brinda mayor tranquilidad si se siente muy ansioso, pero algunas consultas pueden resolverse mediante un llamado telefónico o buscando información en sitios adecuados (p. ej., si necesita información general y consejos sobre el autocuidado). 
Además se aconseja configurar con anticipación la tecnología necesaria para llevar adelante la videoconsulta, verificar el funcionamiento de los dispositivos de audio y video y la conectividad a Internet, y elegir un lugar tranquilo para que se desarrolle la consulta sin interrupciones. Otras recomendaciones incluyen asegurarse de que el profesional con quien tiene la videoconsulta conozca su número de teléfono por si necesitan comunicarse por ese medio en caso de falla en la conexión, mirar a la pantalla durante la consulta, usando la cámara si necesita mostrar algo (p. ej., una lesión en la piel), tomar notas por escrito de las indicaciones y asegurarse de comprender los pasos a seguir.

\section{5) Evidencia sobre la calidad y la seguridad de las videoconsultas}

Los autores de la guía consideran que existe suficiente investigación que sugiere que las videoconsultas usando las TIC, en ámbitos hospitalarios ambulatorios, son seguras para los pacientes de bajo riesgo. Sin embargo, pocas investigaciones han eva- luado el uso de este tipo de consultas en situaciones de epidemia o en ámbitos de atención primaria de la salud. El cuerpo de evidencia disponible está constituido, principalmente, por ensayos clínicos con pocos pacientes, muy seleccionados y sin enfermedades agudas. Si bien no se identificaron riesgos imprevistos, se desconoce su relevancia en el brote actual de COVID-19.

Los estudios cualitativos sugieren que introducir un servicio de teleconsultas en una organización de salud es más difícil de lo que se suele asumir, debido a la necesidad de cambios en los roles organizacionales, en las rutinas y en los procesos. Las experiencias más exitosas se producen cuando no se trata de introducir una nueva tecnología, sino de mejorar el servicio.

Fuente de financiamiento/Conflicto de interés de los autores: La autora pertenece al grupo de investigación IRIHS de la Universidad de Oxford, Reino Unido. No se reportan fuentes específicas de financiamiento ni conflictos de interés.

\section{Comentario}

La actual pandemia de COVID-19, causada por la transmisión del virus SARS-CoV-2, ha impulsado el uso de las TIC en diversas áreas de la vida cotidiana, incluyendo los servicios de salud. La videoconsulta parece ser una herramienta de gran utilidad, ya que contribuye a vincular a los usuarios con los profesionales sanitarios manteniendo la distancia física necesaria para evitar la transmisión del virus.

Sin dejar de lado el uso posible de otros canales de comunicación entre médico y paciente, como podrían ser el teléfono, el correo electrónico, los sistemas de mensajería en portales de salud o los contactos por aplicaciones como WhatsApp u otras redes sociales, cabe remarcar que el contacto visual mediante la videollamada genera un acercamiento con el profesional que ninguno de los otros puede brindarle. Por otro lado, la implementación de la videoconsulta en un entorno digital institucional le brinda un marco a la consulta médica que el resto de los canales de comunicación no posee.

Sin embargo, resulta evidente que no todos los problemas que motivan el contacto de las personas con el sistema de salud pueden ser apropiadamente abordados mediante esta vía de comunicación, uno de los puntos principales que tiene en cuenta la guía resumida. Una de sus fortalezas es su carácter conciso y disponible en varios idiomas. Su principal limitación consiste en que, como señalan sus autores, la evidencia disponible para avalar la eficacia y seguridad de las videoconsultas en atención primaria de la salud es limitada e indirecta, ya que deriva de estudios realizados con pacientes en ámbitos hospitalarios, con condiciones crónicas estables.

Si bien la videoconsulta se posiciona en esta pandemia como una herramienta facilitadora de la comunicación entre profesionales y pacientes, no debemos descuidar en el análisis de su implementación, la diversidad social, económica y cultural de cada comunidad. Esto implica tener en cuenta que se podría aumentar la brecha en la accesibilidad a los cuidados sanitarios de distintas clases sociales y grupos etarios si la implementación de videoconsultas no se acompaña de medidas que tiendan a igualar las oportunidades de acceso a esta TIC.

\section{Conclusiones de la comentadora}

La videoconsulta es una herramienta efectiva en el contexto de la emergencia sanitaria por la pandemia por COVID-19. Más allá del desarrollo de un adecuado marco legal que regule esta actividad, recomendamos que una vez que hayamos dejado atrás estas épocas de aislamiento social preventivo y obligatorio, la continuidad de la teleconsulta esté sujeta a las situaciones en la que estén claros los motivos de su utilización, como los que se enumeran en esta guía en el contexto de la pandemia actual. Por otro lado, como toda nueva tecnología debería ser sometida a un proceso de evaluación de su eficacia, efectividad y eficiencia, incluyendo las dimensiones vinculadas con la experiencia de los pacientes y la seguridad de la provisión de cuidados de salud a través de ella; teniendo en cuenta que en el caso de probarse su efectividad, debería asegurarse que su accesibilidad esté garantizada, procurando disminuir las brechas digitales que afectan actualmente a amplios sectores de la población. Finalmente, debemos tener presente que esta herramienta no debiera reemplazar a la consulta presencial en las situaciones que esta última es la única forma admisible de brindar cuidados de salud.

Analía Paola Cerqueira [ Servicio de Medicina Familiar y Comunitaria, Hospital Italiano de Buenos Aires. analia.cerqueira@hospitalitaliano.org.ar ]

Cerqueira AP. Guía práctica para realizar videoconsultas . Evid Actual Pract Ambul. 2020;23(3):e002063. Comentado de: Greenhalgh T. Video consultations: a guide for practice. BJGP Life, 18 Mar 2020. Disponible en: https://bjgplife.com/2020/03/18/video-consultations-guide-for-practice/

\section{Referencias}

1. Greenhalgh T. Video consultations: a guide for practice; 2020. Available from: https://bjgplife.com/2020/03/18/video-consultations-guide-for-practice/ [Last access: 2020-08-28]. 